\title{
Have the attitudes of Australian squash players towards protective eyewear changed over the past decade?
}

\section{R M Eime, C F Finch}

See end of article for authors' affiliations

.....................

Correspondence to: Professor Finch, Sports Injury Prevention Unit, Department of

Epidemiology and Preventive Medicine, Central and Eastern Clinical School, Alfred Hospital, Melbourne, Victoria 3004, Australia; caroline.finch@ med.monash.edu.au

Accepted 11 April 2002

\begin{abstract}
Objective: To assess indicative trends in the use of protective eyewear by Australian squash players and their attitudes towards its use since 1989.

Methods: Data were extracted from three Australian surveys of squash players conducted in 1989, 1995, and 2000. Responses to directly similar attitudinal questions relating to protective eyewear use from each survey were compared. The proportion of players giving each response was calculated for each survey, along with $95 \%$ confidence intervals for the differences between the 2000 survey and those from the earlier surveys.

Results: Self reported use of protective eyewear ranged from $10.0 \%$ in 1989 , to $8.6 \%$ in 1995 , and $18.8 \%$ in 2000 . However, only $8.9 \%$ of the players surveyed in 2000 actually wore appropriate standards approved/polycarbonate lens eyewear. This can be compared with $8.0 \%$ and $2.0 \%$ of players who reported wearing appropriate polycarbonate lens eyewear in the 1989 and 1995 surveys respectively. Compared with the 1995 survey, significantly more players in 2000 believed that more players should wear protective eyewear (95\% confidence interval (CI) for difference 1 to 18). A significantly higher proportion of players also supported the compulsory use of protective eyewear by juniors in 2000 than in both 1989 (95\% Cl for difference 6 to 24) and 1995 (95\% Cl for difference 5 to 22). No other attitudes had significantly changed over the decade.

Conclusion: These data suggest that self reported use of protective eyewear has probably increased over the past decade. However, many players report wearing inappropriate eyewear. A transition from positive attitudes to appropriate eyewear behaviours is required before mandatory protective eyewear use can be effectively introduced.
\end{abstract}

$\mathrm{S}$ quash is a popular sport, with about 15 million players in 135 nations participating annually on 52575 courts. ${ }^{12}$ It has been shown to be one of the sports most commonly associated with eye injuries, accounting for $7.0-49.0 \%$ of all sporting eye injuries, depending on the source of the injury data. ${ }^{3-8}$ Reported eye injury incidence ranges from 3.7 to 33.3 per 100000 playing sessions. ${ }^{3-12}$ The most recent Australian study reported 64 eye injuries per 100000 squash participants. ${ }^{13}$ Although most eye injuries are not severe, they have the potential to cause permanent visual impairment. $^{8}{ }^{13} 14$

Eye injuries in sports are almost completely preventable with standards approved polycarbonate protective eyewear. ${ }^{815}{ }^{16}$ However, a number of studies have shown that only $9-10 \%$ of squash players choose to wear protective eyewear. ${ }^{6111^{18}}$ Some players report wearing eyewear that is either not protective or that is actually risk enhancing, such as lensless eyewear, prescription glasses, industrial eyewear, and contact lenses..$^{13^{19-21}}$ It has been suggested that prevailing attitudes towards protective equipment are a major influence of protective equipment behaviours. ${ }^{22} 23$

To date, there have only been four published studies, two Australian $^{11}{ }^{17}$ and two British ${ }^{6}{ }^{18}$, investigating players' self reported eyewear behaviour. Three of these studies also reported players' attitudes towards protective eyewear use. $^{61117}$ A third Australian study has recently been conducted ${ }^{24}$ Consistently, these studies have found few adult players to be supportive of compulsory protective eyewear, but many believe it should be compulsory for junior players. ${ }^{6} 111724$

Since 1989, three surveys of squash players' attitudes towards, and use of, protective eyewear have been conducted in Australia. Protective eyewear was made compulsory for junior and doubles players throughout Australia in 1997. Since this regulation was introduced, there have been no concerted efforts to further promote protective eyewear use. In the absence of such efforts, especially concentrated on the adult population who are not the target of this regulation, it could be expected that there would be no substantial change in rates of protective eyewear use by squash players. The aim of this study was to describe the indicative trends in protective eyewear use and attitudes towards such use, to see if this was, indeed, the case.

\section{METHODS}

A search of the literature specific to squash players' protective eyewear behaviours and associated attitudes towards its use was conducted. Three studies, all Australian, conducted in $1989,{ }^{11} 1995,{ }^{17}$ and $2000^{24}$ were identified as having similar methodologies and survey questionnaires. Table 1 describes the key methodological methods used in each of these studies. Although the studies were conducted in different Australian states, and different sampling frames were used, they asked similar questions about player attitudes.

The numbers and percentages of squash players responding to behavioural and attitudinal questions relating to protective eyewear use was extracted from each of the published studies and compared. For each study, protective eyewear rates during squash were determined from players' self reports. Information about the type of eyewear used was also obtained, and the reported eyewear was categorised as "appropriate" or "inappropriate". Appropriate eyewear was defined as polycarbonate lens/standards approved squash eyewear. As no other eyewear is suitably protective, ${ }^{5139-21}$ all other eyewear was classified as inappropriate.

In each of the three studies, players were asked to report their attitudes towards four or five statements about 
Table 1 Methodology comparisons between three Australian studies of players' attitudes towards the use of protective eyewear

\begin{tabular}{|c|c|c|c|}
\hline & $1990^{11}$ & $1998^{17}$ & $2000^{24}$ \\
\hline City of study & Perth & Melbourne & Melbourne \\
\hline Timing of survey & 1989 & July-October, 1995 & June, 2000 \\
\hline Sampling of venues & Not known $(n=3)$ & $\begin{array}{l}\text { Randomly selected venues from Eastern } \\
\text { metropolitan Melbourne ( } \mathrm{n}=7)\end{array}$ & $\begin{array}{l}\text { Randomly selected venues from Eastern } \\
\text { metropolitan Melbourne ( } n=3)\end{array}$ \\
\hline Selection of players & $\begin{array}{l}\text { Distribution by hand to players on } 1 \\
\text { particular night }\end{array}$ & $\begin{array}{l}350 \text { questionnaires left at reception desk } \\
\text { for players to pick up }\end{array}$ & $\begin{array}{l}\text { All adult squash players presenting at } \\
\text { randomly selected sessions over a } 3 \text { week } \\
\text { period }\end{array}$ \\
\hline $\begin{array}{l}\text { Type of players } \\
\text { surveyed }\end{array}$ & Pennant squash players & $\begin{array}{l}\text { All squash players attending one of the } \\
\text { venues }\end{array}$ & All adult squash players \\
\hline $\begin{array}{l}\text { Number of survey } \\
\text { respondents }\end{array}$ & 165 & 197 & 303 \\
\hline Response rate & $99 \%$ of players approached & $56 \%$ of distributed questionnaires & $98 \%$ of players approached \\
\hline Age & Not reported & \multicolumn{2}{|c|}{$\begin{array}{l}40 \% \text { aged } 24-44 \text { years, } 15 \% \text { aged } 15-22 \text { Mean } 41 \text { years. Adults only } \\
\text { years }\end{array}$} \\
\hline Sex & $53 \%$ male & $65 \%$ male & $66 \%$ male \\
\hline Eyewear use question & $\begin{array}{l}\text { Protective eyewear use questions not } \\
\text { stated }\end{array}$ & \multicolumn{2}{|c|}{$\begin{array}{l}\text { "Do you wear protective eyewear?" Type of" Do you wear protective eyewear?" Type of } \\
\text { protective eyewear worn }\end{array}$} \\
\hline
\end{tabular}

Table heading shows year of study and reference.

protective eyewear use on a five point Likert scale (strongly agree, agree, uncertain, disagree, strongly disagree) (table 2 ). The wording of three of the statements was exactly the same in all surveys. Players' attitudes towards one identically worded statement were available for the 1995 and 2000 studies only. The remaining statement, although having the same meaning in all studies, was worded: "protective eyewear should be made compulsory" in the $1989^{11}$ and $1995^{17}$ studies. In the 2000 study, the words "for all players" were included at the end of this statement.

For comparative purposes, responses in the "strongly agree" and "agree" categories were combined, as was the data in the "strongly disagree" and "disagree" categories. For four of the attitudinal questions the "strongly agree/agree" response was the most desirable (table 2). For the remaining question, the "strongly disagree/disagree" response was most desirable (table 2). Ninety five percent confidence intervals were calculated for the differences in attitudes from the 2000 survey and earlier surveys. ${ }^{25} \mathrm{~A}$ confidence interval containing the value " 0 " was taken to indicate no significant difference between the comparison surveys.

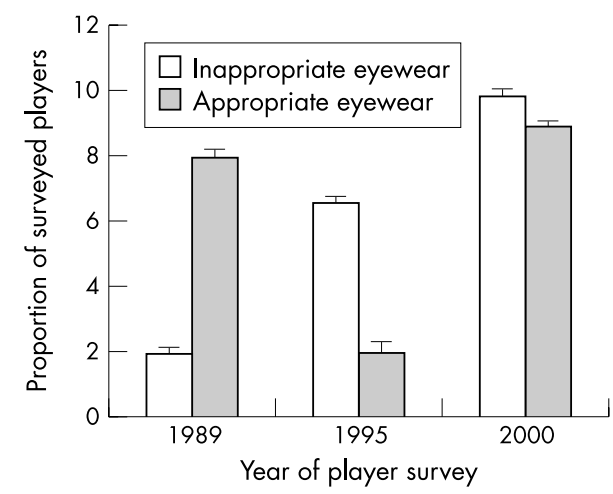

Figure 1 Indicative trends in self reported eyewear use by Australian squash players, 1989-2000. The 95\% confidence interval is given.

\section{RESULTS}

Protective eyewear behaviours

Figure 1 summarises the rates of protective eyewear wearing in the three studies. Over the 11 year period, self reported protective eyewear use changed from $10 \%$ in 1989 to $8.6 \%$ in 1995 , then increased to $18.8 \%$ in 2000 . However, the rate of self reported use of inappropriate eyewear also increased over time. Nevertheless, levels of appropriate protective eyewear use were highest in the most recent survey.

\section{Attitudes towards protective eyewear use}

Table 2 presents a comparison of players' attitudes across the three studies. Overall, this suggests that there have not been major changes in players' attitudes towards the risk of eye injuries since 1989. There was a slight, but non-significant, increase in players' positive responses to the statement that eye injuries are a particular problem in squash, from 1995 to 2000, with comparison data not available from the 1989 survey. In the 2000 survey, significantly more support for general protective eyewear use was given with $67.0 \%$ of players stating that they believed more players should use protective eyewear, compared with only $57.0 \%$ of players in 1995 . There was no significant difference between the 2000 and 1989 survey responses to this attitudinal statement.

The extent of players' positive views towards the implementation of compulsory use of protective eyewear for all players ranged from $17.0 \%$ of all surveyed players in 1989 and $16.0 \%$ in 1995 to $24.0 \%$ in 2000 . However, this increase was not significant. Although most players in 2000 did not support compulsory protective eyewear for all players, a high proportion $(69.0 \%)$ were in favour of it for junior players. There was a significantly higher level of support for junior eyewear use in 2000, compared with both earlier surveys. Most players in each study indicated that they would not stop playing squash if protective eyewear was made compulsory, and this attitude did not vary significantly across the studies.

\section{DISCUSSION}

Before compulsory use of any form of protective equipment can be effectively implemented, efforts need to be made to 
Table 2 Comparison of players' attitudes towards protective eyewear use in squash from three Australian studies

\begin{tabular}{|c|c|c|c|c|c|}
\hline & \multicolumn{3}{|c|}{ Percentage of all players } & \multicolumn{2}{|c|}{$\begin{array}{l}95 \% \text { confidence intervals for the differences } \\
\text { between the } 2000 \text { survey results and earlier } \\
\text { surveys }\end{array}$} \\
\hline & $\begin{array}{l}2000^{24}(n=303) \\
(A)\end{array}$ & $\begin{array}{l}1995^{17}(n=197) \\
\text { (B) }\end{array}$ & $\begin{array}{l}1989^{11}(n=165) \\
\text { (C) }\end{array}$ & $2000 \vee 1995(\mathrm{~A}-\mathrm{B})$ & $2000 \vee 1989(A-C)$ \\
\hline \multicolumn{6}{|l|}{ Strongly agree/agree } \\
\hline $\begin{array}{l}\text { Eye injuries are a particular problem in } \\
\text { squash }\end{array}$ & 61 & 57 & - & $(-5$ to 13$)$ & - \\
\hline $\begin{array}{l}\text { More players should use protective } \\
\text { eyewear }\end{array}$ & 67 & 57 & 65 & (1 to 18$)$ & $(-7$ to 11$)$ \\
\hline $\begin{array}{l}\text { Protective eyewear should be made } \\
\text { compulsory for all players }\end{array}$ & 24 & 16 & 17 & (0 to 15 ) & $(-1$ to 14$)$ \\
\hline $\begin{array}{l}\text { Protective eyewear should be made } \\
\text { compulsory for junior players }\end{array}$ & 69 & 56 & 54 & (5 to 22$)$ & (6 to 24$)$ \\
\hline $\begin{array}{l}\text { Strongly disagree/disagree } \\
\text { I would stop playing if protective eyewear } \\
\text { was made compulsory }\end{array}$ & 65 & 64 & 71 & $(-8$ to 9$)$ & $(-15$ to 2$)$ \\
\hline
\end{tabular}

address player attitudes and how these have changed over time. ${ }^{26}$ If voluntary use of protective equipment among players is not at an acceptable level before the introduction of a regulation requiring its use, then in the absence of strong penalties and regulatory monitoring, its introduction is unlikely to be successful as there will be little support for it. As has been shown with the introduction of mandatory bicycle helmets, a broad level of acceptance for protective equipment is essential before mandatory use can be successful. ${ }^{26}$ For example, voluntary use of bicycle helmets in Victoria, Australia was raised to $36 \%$ before mandatory legislation. ${ }^{26}$ Attention should therefore be given towards player education about protective equipment use before a regulation is introduced. Identification of player attitudes towards such equipment is necessary to guide this process.

This study has compared indicative results from three Australian studies, which surveyed squash player behaviours and attitudes associated with protective eyewear use. It is recognised that there are limitations associated with these comparisons, as the studies did not all have consistent methodology. For example, the 1989 survey included only competition players. Players with more squash experience are significantly more likely to report playing with protective eyewear, than those players with less experience. ${ }^{24}$ Whereas only adult players participated in the 2000 survey, there was a small proportion of junior players in the 1995 survey, and the age distribution of players from the 1989 survey was not reported, although it was probably mainly adults. The 1995 survey relied on a volunteer sample of players and this may have led to a biased sample, as players that wore protective eyewear may have been more inclined to participate in the survey. Alternatively, it could be that the method of player recruitment in the 1995 study was so different from that in the other studies that it influenced the results. Given these limitations, it is possible that the reported rates of eyewear use in the two earlier surveys were overestimated. However, it is unlikely that this would have led to a differential bias in the reporting of appropriate versus inappropriate eyewear use. The information available did not allow a direct comparison of player characteristics across surveys to be made. It should also be pointed out that each survey potentially excluded any player who was absent because of an eye injury at the time of the survey.

Overall, the indicative trends presented in this paper suggest that self reported voluntary protective eyewear use has nearly doubled since 1989. There was no a priori expectation that rates of protective eyewear use would have changed over the past decade, as there has been no active promotion of protective eyewear throughout this period in adult players. However, the high, and apparently increasing, proportion of players reporting inappropriate eyewear use is a concern. Squash standards approved polycarbonate lens eyewear is the only eyewear that provides suitable protection. All other eyewear reported has been shown to potentially heighten the risk of ocular damage. ${ }^{6}{ }^{13} 27$

A comparison of the attitudes reported in these three Australian squash player surveys suggests an encouraging change in players' attitudes towards the implementation of compulsory protective eyewear for junior players. However, the proportion of players favouring compulsory protective eyewear for all players is much lower than that supporting use of such equipment by junior players. The compulsory use of protective eyewear for junior players introduced in 1997 in Australia ${ }^{16}$ may have contributed to these trends.

Use of protective eyewear while playing squash is compulsory at many clubs in certain states and provinces in the United States of America and Canada. ${ }^{28}$ However, its use is not as yet mandatory for Australian adult players, nor for players from the United Kingdom or Europe. ${ }^{16}$ The implementation of mandatory protective eyewear use in parts of the United States of America was reportedly met with minimal player resistance and has eliminated the occurrence of most eye injuries caused by squash. ${ }^{13}$

It is expected that, if protective eyewear use was made compulsory for adult squash players in Australia, the occurrence of eye injuries in squash would subsequently be minimised. Ideally, future strategies for eye injury prevention in squash will assist players in the transition to appropriate protective eyewear use and their acceptance of this behaviour change. It is possible that, if protective eyewear is made compulsory for all players before, or without, a coincident increase in knowledge about the risks of injury and what is appropriate eyewear, then there may not be high compliance with this ruling. ${ }^{24}{ }^{29}$ Nonetheless, it is likely that managers of squash venues would support this regulation and not risk litigation from injured players.

In summary, this study has found that many players do not wear suitable protective eyewear when playing squash. Indicative trends suggest an increasing proportion who report wearing protective eyewear, but a large number of players actually using inappropriate eyewear. A lack of knowledge about the risks of eye injury and of what eyewear is suitably protective may contribute to the low rates of protective eyewear use. However, there is also a suggestion that players' attitudes do not currently support widespread mandatory protective eyewear for all players. It is recommended that the results of this study be considered by squash bodies, eyewear manufacturers, venue managers, and players associations for the development of eye injury prevention strategies for this sport. Future research is required to explore strategies to 


\section{Take home message}

It is important to understand the attitudes of squash players towards protective eyewear before its use is made compulsory. Many players do not wear appropriate eyewear when playing. Education strategies are required to increase the use of appropriate protective eyewear, while decreasing the use of inappropriate eyewear.

enhance protective eyewear through squash venues, as well the best ways to educate players of the risk of eye injury and of appropriate eyewear for the game of squash.

\section{ACKNOWLEDGEMENTS}

Mr Paul Vear, the Executive Director of the Victorian Squash Federation, is thanked for his support of this project.

\section{Authors' affiliations}

R M Eime, C F Finch, Sports Injury Prevention Research Unit, Department of Epidemiology and Preventive Medicine, Monash University, Prahran, Australia

\section{REFERENCES}

1 World Squash Federation. Squash courts (cited in March 2000). www.worldsquash.org/rules/courts. htm.

2 Wallbutton T. The history of squash (cited January 2001). http://www. squash.org/WSF/history.htm.

3 Barrell GV, Cooper PJ, Elkington AR, et al. Squash ball to eye ball: the likelihood of squash players incurring an eye injury. Br J Sports Med 1981;283:893-5.

4 MacEwen CJ. Sport associated eye injury: a casualty department survey. BrJ Ophthalmol 1987;71:701-5.

5 Jones NP. Eye injuries in sport: an increasing problem. Br J Sports Med 1987;21:168

6 Loran D. Eye injuries in squash. Optician Mar 1992:18-26.

7 Fong LP. Eye injuries in Victoria, Australia. Med J Aust 1995;162:65-8.
8 Vinger P. A practical guide for sports eye protection. Physician and Sports Medicine 2000;28: 1-13.

9 Clemett RS, Fairhurst SM. Head injuries from squash: a prospective study. N Z Med J 1980;92:1-3.

10 Easterbrook $M$. Eye protection in racquet sports. Clinics in Sports Medicine 1988;2:253-66.

11 Genovese MT, Lenzo NP, Lim RK, et al. Eye injuries among pennant squash players and their attitudes towards protective eyewear. Med J Aust 1990;153:655-8.

12 Vinger P. The eye and sport medicine. Philadelphia: Harper and Row, 1991.

13 Fong LP. Sports-related eye injuries. Med J Aust 1994;160:743-50.

14 Whyte JD. Eye injuries. Athletic Training 1987;22:207-10.

15 International Federation of Sports Medicine. Eye injuries and eye protection in sports. Br J Sports Med 1989;23:59-60.

16 Squash Australia. Protective eyewear policy. Synergy 1998:32-3.

17 Finch $C$, Vear $P$. What do adult squash players think about protective eyewear? Br J Sports Med 1998;32:155-61.

18 Pardhan S, Shacklock P, Weatherill J. Sport-related eye trauma: a survey of the presentation of eye injuries to a casualty clinic and the use of protective eye-wear. Eye 1995;9:S50-3.

19 Easterbrook M. Eye protection in racket sports: an update. Physician and Sports Medicine 1987;15:180-5;188;192.

20 Bishop PJ, Kozey J, Caldwell G. Performance of eye protectors for squash and racquetball. Physician and Sports Medicine 1982;10:63-9.

21 International Federation of Sports Medicine. Eye injuries and eye protectors in sports. Athletic Therapy Today 1999;4:6-8.

22 Wong TY, Seet B. A behavioral analysis of eye protection use by soldiers. Mil Med 1997; 162:744-8.

23 Gellar E. The psychology of safety: how to improve behaviors and attitudes on the job. Boca Raton: CRC Press, 2000.

24 Eime RM, Finch CF, Sherman CF, et al. Are squash players protecting their eyes? Injury Prevention 2002; in press.

25 Kirkwood B. Essentials of medical statistics. London: Blackwell Science, 1988.

26 Cameron MH, Vulcan AP, Finch CF, et al. Mandatory bicycle helmet use following a decade of helmet promotion in Victoria, Australia: an evaluation. Accident Analysis and Prevention 1994;26:325-37.

27 Pashby TJ. Eye injuries in Canadian sports and recreational activities. Can J Ophthalmol 1992:27:226-9.

28 David DB, Shah P, Whittaker C, et al. Ocular protection in squash clubs: time for a change? Eye 1995;9:575-7

29 Finch C. Teenagers' attitudes towards bicycle helmets three years after the introduction of mandatory wearing. Injury Prevention 1996;2:126-30. 